\title{
Characterizing vertical forest structure using small-footprint airborne LiDAR
}

\author{
Daniel A. Zimble ${ }^{\mathrm{a}}$, David L. Evans ${ }^{\mathrm{b}, *}$, George C. Carlson ${ }^{\mathrm{c}}$, Robert C. Parker ${ }^{\mathrm{b}}$, \\ Stephen C. Grado ${ }^{\mathrm{b}}$, Patrick D. Gerard ${ }^{\mathrm{d}}$ \\ ${ }^{\text {a }}$ ESRI, Vienna, VA, USA \\ ${ }^{\mathrm{b}}$ Department of Forestry, Mississippi State University, Box 9681, 100 Stone Boulevard, Thompson Hall, Mississippi State, MS 39762, USA \\ ${ }^{\mathrm{c}}$ Resource Management Technologies, Vancouver, WA, USA \\ ${ }^{\mathrm{d}}$ Agriculture Information Science and Education, Mississippi State University, Mississippi State, MS, USA
}

Received 27 January 2003; received in revised form 11 April 2003; accepted 21 May 2003

\begin{abstract}
Characterization of forest attributes at fine scales is necessary to manage terrestrial resources in a manner that replicates, as closely as possible, natural ecological conditions. In forested ecosystems, management decisions are driven by variables such as forest composition, forest structure (both vertical and horizontal), and other ancillary data (i.e., topography, soils, slope, aspect, and disturbance regime dynamics). Vertical forest structure is difficult to quantify and yet is an important component in the decision-making process. This study investigated the use of light detection and ranging (LiDAR) data for classifying this attribute at landscape scales for inclusion into decisionsupport systems. Analysis of field-derived tree height variance demonstrated that this metric could distinguish between two classes of vertical forest structure. Analysis of LiDAR-derived tree height variance demonstrated that differences between single-story and multistory vertical structural classes could be detected. Landscape-scale classification of the two structure classes was $97 \%$ accurate. This study suggested that within forest types of the Intermountain West region of the United States, LiDAR-derived tree heights could be useful in the detection of differences in the continuous, nonthematic nature of vertical forest structure with acceptable accuracies.
\end{abstract}

(C) 2003 Elsevier Inc. All rights reserved.

Keywords: Remote sensing; Tree measurement; LiDAR; Forest structure; Intermountain West

\section{Introduction}

Forest composition and structure are difficult to assess over large, remote areas but represent important information needed to guide multiple-use forest management. Remote sensing, global positioning systems (GPS), and geographic information systems (GIS) are the modern tools for collection and manipulation of such information. Light detection and ranging (LiDAR; e.g., small-footprint, multireturn) is a remote sensing tool that is proving to be particularly useful for collection of measurement data for natural resource assessments.

While many practical applications of LiDAR technology focus on producing digital elevation models (DEMs;

\footnotetext{
* Corresponding author. Tel.: +1-662-325-2796; fax: +1-662-325-8726

E-mail address: dle@rs.cfr.msstate.edu (D.L. Evans).
}

Kraus \& Pfeifer, 1998; Petzold, Reiss, \& Stossel, 1999), the potential for using LiDAR data to derive forest measurement information has also received strong attention over a significant period of time (Hyyppä, Kelle, Lehikoinen, \& Inkinen, 2001; Lefsky et al., 1999; Means et al., 1999; Nelson, Krabill, \& Tonelli, 1988; Nilsson, 1996; Persson, Holmgren, \& Söderman, 2002). Until recently, however, knowledge has been more limited on the utilization of LiDAR data to map forest structure (both vertical and horizontal) at landscape scales. Recent studies with logical extensions to landscape scales point to the utility of LiDAR data in forest structure characterization (Hudak, Lefsky, Cohen, \& Berterretche, 2002; Næsset, 2002; Næsset \& Økland, 2002). This body of evidence led us to examine the utility of LiDAR data for quantitative characterization of vertical and horizontal forest structure at landscape scales as inputs to habitat decision-support systems (DSS). 


\subsection{Environmental decision-support systems}

The need for effective decision-support tools has led to a variety of environmental or ecological DSS that attempt to integrate current ecological theory with existing environmental information to manage ecosystems in a sustainable manner. One such ecological DSS is the ecosystem diversity matrix (EDM), implemented jointly by Boise Cascade and the U.S. Forest Service on landscape-level test beds in five states (Haufler, Mehl, \& Roloff, 1999).

The Idaho Southern Batholith Landscape (ISBL), one of the EDM test beds, uses a combination of forest composition, structure, and historical disturbance regime information as inputs for the development of an ecosystem diversity classification system to determine what, where, how, and when various forestry activities will or will not occur. The ISBL EDM (from here on referred to as EDM) forest composition classification (or habitat type) is based on the combination of various vegetation species assemblages (i.e., tree, shrub, and herbaceous species). EDM incorporates environmental gradient information, such as elevation and slope, that is used to characterize species assemblages as "warm-dry" or "cool-moist" for final habitat type classification. In addition to habitat types, the EDM also incorporates vegetation growth stage (VGS) information, which relates various levels of canopy closure, vertical structure, and tree size together to describe a relative structural "stage" within a given successional pathway. Habitat type and VGS classifications are used in tandem to produce the EDM, a landscape-level description of ecological diversity within the ISBL.

Data used in the EDM were from a variety of sources, including existing field inventory data and geospatial information such as remotely sensed imagery (e.g., Landsat TM classification of vegetation). When this LiDAR project was being initiated, the VGS component of the EDM classifications had not been verified across the region. Moreover, an accuracy assessment was not available for the Landsat TM classifications. During the planning stages of this work, classification maps developed for the EDM were inspected in the field to determine if they could be used for stratification of field plots by vegetation type and structure. These initial field observations indicated inconsistencies between observed vs. expected vegetation conditions. Consequently, this project was designed to examine the potential of using data from a small-footprint, multireturn LiDAR system to more consistently map vertical forest structure for use in development of the VGS classification.

\subsection{LiDAR and vertical forest structure}

One of the most difficult components to quantify in forested ecosystems is overall forest structure, or the threedimensional organization of objects. Vertical forest struc- ture, defined as "...the bottom to top configuration of above ground vegetation within a forest stand" (Brokaw \& Lent, 1999), is particularly difficult to quantify, although it is certainly important for making management decisions. Changes in vertical forest structure affect both microclimatic patterns and processes directly (Brokaw \& Lent, 1999) and have been shown to impact the behavior and distribution of various avian species (Martin, 1988; Maurer \& Whitmore, 1981; Robinson \& Holmes, 1982). Documentation of vertical forest structure at landscape scales will be extremely useful for making regional forest management decisions.

LiDAR systems create spatial data sets that provide insights into numerous ecological conditions while monitoring changes within those conditions. It is possible to use information inherent in LiDAR data to describe stand structure attributes (basal area and biomass; Lefsky et al., 1999). A metric, such as tree height variance, could be used to classify various vertical forest structural configurations or species. For example, Brandtberg, Warner, Landenberger, and McGraw (2002) examined variables, including standard deviation, as inputs to linear discriminant analysis and found limited capabilities to classify some deciduous tree species. Accurate forest structure classifications with LiDAR data (described here as single-story or multistory) should improve VGS classifications since vertical structure is one of three components used to derive the VGS.

\subsection{Study objectives}

One conceptual framework for habitat structure linked references commonly used to describe the "physical arrangement of objects in space" to standardize what is meant by habitat structure (McCoy \& Bell, 1991). Our study adopted this concept for describing forest structure, in general, and vertical forest structure, in particular.

Vertical forest structure was defined as the distribution of tree heights within a forest stand. Horizontal structure, while not specifically studied, was defined for reference as the distribution of percent canopy closure. EDM is an ecological DSS that was designed for use at landscape scales. Hence, this study focused on how information relating to vertical structure can be derived and mapped from smallfootprint, multireturn LiDAR data at such scales. Tree height variance derived from both field and LiDAR data was chosen as the metric to distinguish between categories of vertical structure. It was hypothesized that there were no significant differences between field- and LiDAR-derived tree height variances.

The specific objectives of this study were to: (1) determine if tree height variances can be used to separate two vertical structure classes (single-story vs. multistory); (2) establish whether any significant differences exist between field- and LiDAR-derived tree height variances; and (3) develop a methodology for mapping the distribution of vertical structure at landscape scales. 


\section{Methods}

\subsection{The Idaho Southern Batholith Landscape}

The planning landscape (the ISBL) located in central Idaho (Fig. 1) was derived from research used to delineate relatively homogeneous sections and subsections within the Idaho Batholith Landscape (Mehl et al., 1998). Forests within the ISBL region are dominated by various configurations of: (1) Douglas-fir (Pseudotsuga menziesii [Mirb.] Franco.), (2) grand fir (Abies grandis [Doug.] Lindl.), (3) subalpine fir (Abies lasiocarpa [Hook.] Nutt.), (4) Englemann spruce (Picea engelmannii [Parry]), (5) ponderosa pine (Pinus ponderosa Laws.), and (6) lodgepole pine (Pinus contorta [Doug.]) These forests have canopy closures typically less than $60 \%$. The total area covered within the two research blocks (designated NE and SW on Fig. 1) is approximately 10,000 acres (4046.86 ha).

\subsection{Field data collection and analysis}

Field data were collected in Idaho during the summer of 2000. These data were used to test for differences between field- and LiDAR-derived tree height variances. Height to the top of the live crown was measured for 837 trees $[\geq 6.0$ in. dbh (diameter at breast height)] within 49 circular 0.20 acre (0.081-ha) plots (12 single-story plots and 37 multistory plots). Preexisting maps of stand structure classes, on field inspection, proved to be too inaccurate to use to establish a stratified random sample by condition. Plot site selection, therefore, was primarily made by examination of digital orthophoto quadrangles of the area. Real-time differ-

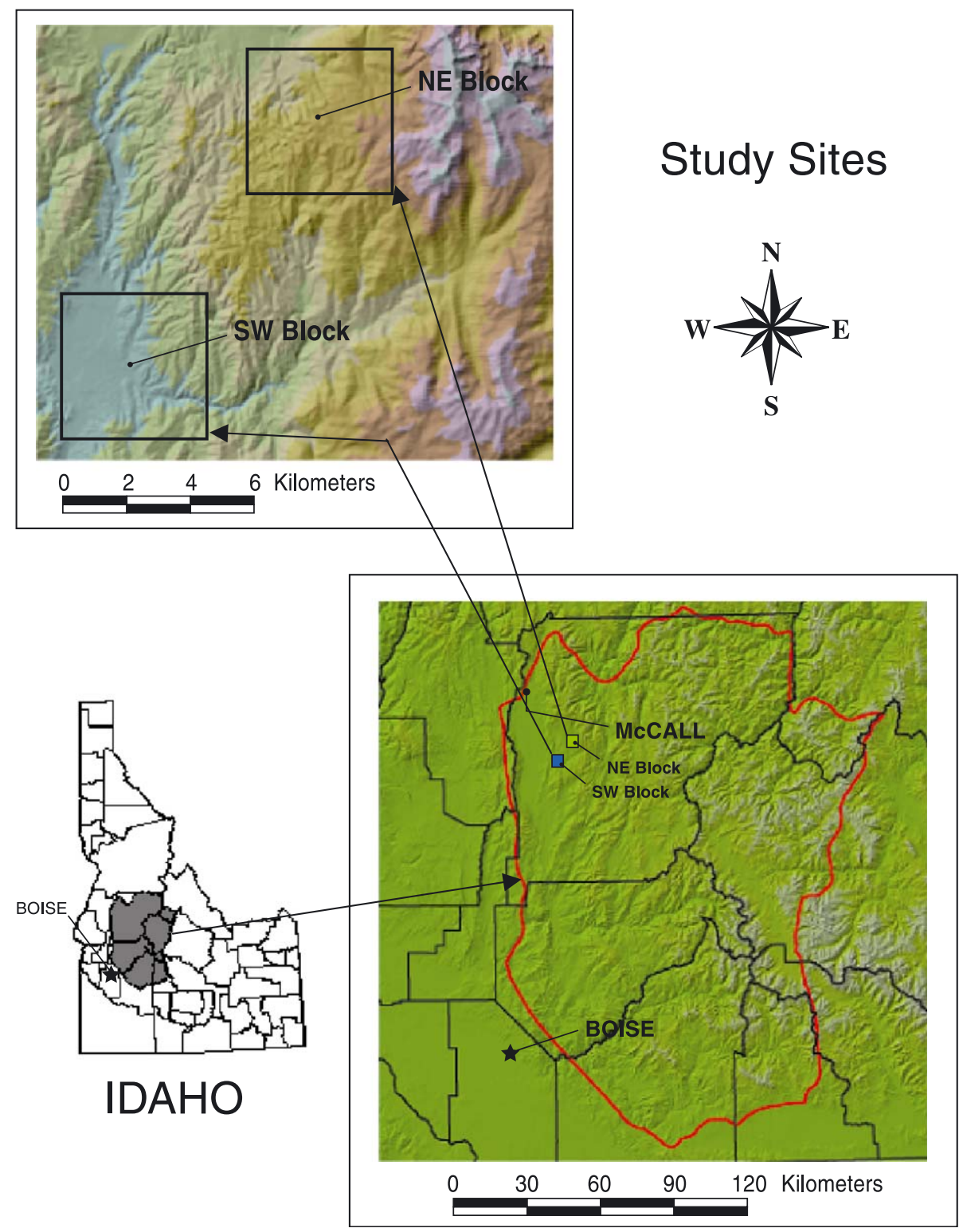

Fig. 1. The location of the NE and SW research blocks (black outlined boxes) within the ISBL study site (red outline) 
ential GPS was used to fix plot locations on both blocks within reasonable walking distance from roads as the rugged terrain precluded sampling all areas due to time constraints.

An ocular classification of vertical structure classes (single-story or multistory) was made on the field plot. The classes were later confirmed by using the groundmeasured tree heights to determine height variability. It was important to demonstrate statistically that single-story plots represented one class while multistory plots represented multiple classes. A significant departure away from the single-story condition would confirm the other class (multistory). All single-story plots were tested using an analysis of variance (ANOVA) procedure to verify that they could be considered a single vertical structure class. Levene's test (Levene, 1960) was used to test the equality of tree height variances at the 5\% significance level.

A generalized linear model (GLM) approach was used to determine if multistory tree height variance significantly departed from single-story tree height variance. Variance distributions followed a scaled chi-square distribution (or, equivalently, a gamma distribution). The GLM is appropriate for analysis of such distributions so a generalized likelihood ratio test was used to determine if any significant separability existed between the two structure classes.

\subsection{LiDAR data collection and analysis}

A small-footprint, multireturn LiDAR mission flown by EarthData Technologies ${ }^{1}$ on October 12, 1998 provided complete coverage of both research blocks (16 flight lines per block) at a nominal post spacing of approximately 2.0 $\mathrm{m}$. The AeroScan system used for this mission was capable of recording up to five returns per outgoing shot based on a minimum distance between returns and relative return intensity. The average mission altitude of approximately $1067 \mathrm{~m}$ above terrain, combined with a $25^{\circ}$ scan angle, produced postpoints approximately $0.3 \mathrm{~m}$ in diameter across an average swath width of $473 \mathrm{~m}$.

Probable ground returns were identified using a groundfinding algorithm developed by EarthData Technologies. LiDAR data sets were used to produce canopy and ground DEMs using a linear interpolation technique $(0.20 \mathrm{~m}$ cell resolution). Both DEMs were incorporated into a spatial model developed to derive tree heights based on procedures adopted with modifications from McCombs, Roberts, and Evans (2003).

Brandtberg et al. (2002) utilized a technique of data segmentation that matched ground- and LiDAR-derived crown areas to determine tree locations and heights. Popescu, Wynne, and Nelson (2002) utilized a variable search window based on tree heights for tree identification and measurement. The tree identification and height-finding model used in this project relied on detection of differences

\footnotetext{
${ }^{1}$ Mention of company or product names is for information only and does not constitute official endorsement by the Mississippi State University.
}

in relative density of local maxima in the LiDAR canopy surface.

First, a 3-ft (0.9-m) radius circular search window (based on minimum crown radius of trees measured in the field) was passed over the canopy surface to identify maxima that might represent tree tops. The locations of these local maxima were used to partition the study area into three categories of relative assumed stem density (low, medium, and high).

The second step involved determination within each of the three stem density categories - the relative height rank of pixels in relationship to their neighbors. Adjoining pixels that were higher than $85 \%$ of their neighbors were combined into clumps that were assumed to include the peaks of tree crowns. All clumps smaller than the expected minimum size of crowns based on field data were eliminated from the data sets. The maximum height and location of that height measurement were then derived for each clump based on the difference between the LiDAR canopy and ground DEMs. This provided a set of tree locations and associated heights that could be used in subsequent operations to examine height variability across the study area.

Since trees measured in the field were selected by minimum dbh ( $\geq 6.0$ in.), and not by absolute height, it was important to exclude trees visible in the LiDAR data that represented trees which were $\leq 6.0 \mathrm{in}$. dbh from the analysis. A nonlinear regression model was developed from tree measurements to model tree heights based on dbh and stem densities (Parker \& Evans, in press). A height threshold of $18.7 \mathrm{ft}(5.7 \mathrm{~m})$ was chosen based on the regression model estimate that 6-in. dbh trees had an average height of $22.0 \mathrm{ft}$ $(6.7 \mathrm{~m})$. The difference between the predicted and utilized height thresholds takes into consideration the accepted understanding that LiDAR generally underestimates tree heights (Eggleston, 2001; Nilsson, 1996). The tree height threshold was applied to remove any trees $<18.7 \mathrm{ft}(5.7 \mathrm{~m})$, resulting in a spatial data set detailing the predicted distribution of trees $\geq 6.0$ in. dbh (Fig. 2a and b). The resulting tree locations and heights were converted to point coverages and then clipped to plot boundaries using a polygon coverage derived by buffering real-time differential GPS plot centers with the 0.20 -acre (0.081-ha) plot radius (Fig. 2c).

Statistical tests used with field measurements were applied to LiDAR-derived tree heights to determine any departures from the single-story structure class. Likewise, the same ANOVA (Levene's test) was used to verify that single-story plots were indeed a single class. The same generalized linear model, used for the field data analysis, was applied. The generalized likelihood ratio test was used to test the two LiDAR-derived structure classes at a $5 \%$ significance level.

\subsection{Field vs. LiDAR data analysis}

Two ANOVAs were used to determine if LiDAR-derived tree height variances were different from field-derived tree 
a.

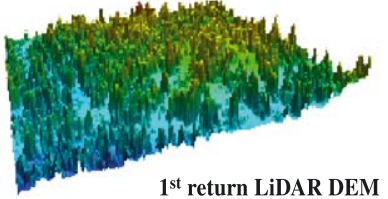

b.

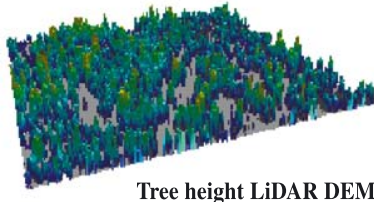

c.

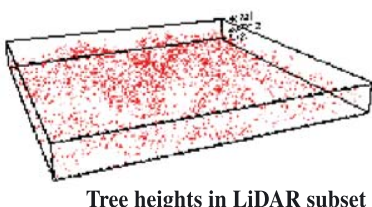

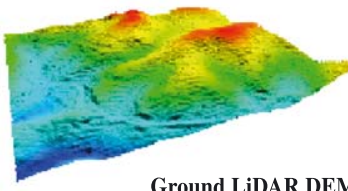

Ground LiDAR DEM
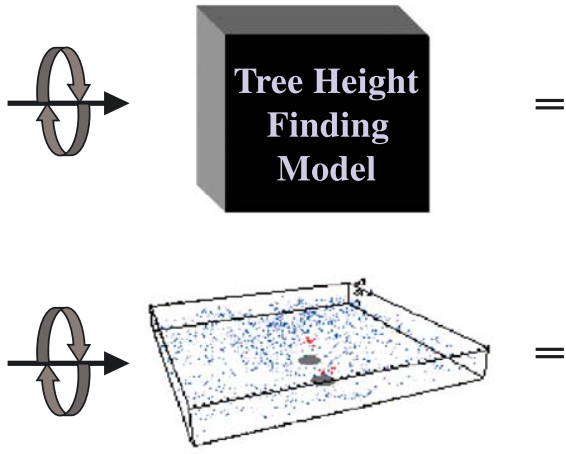

Location of plot tree heights in LiDAR subset
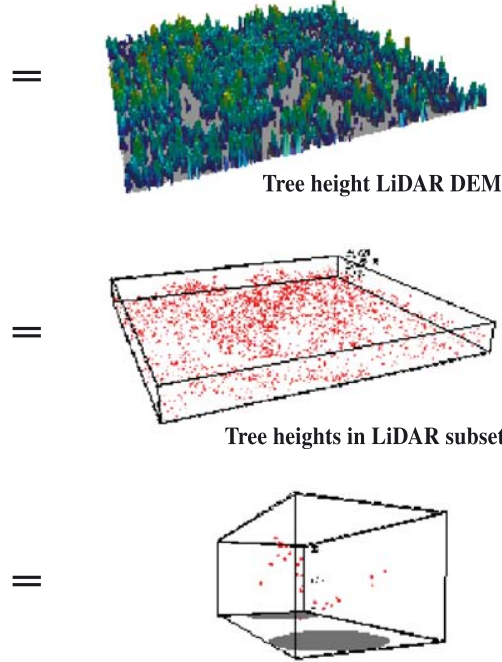

Tree heights within plots

Fig. 2. Processes used to derive tree height information from LiDAR data. (a) Subtract the ground from first return LiDAR DEMs to yield forest height surface. (b) Forest height surface is processed using a tree height-finding model (adopted from McCombs et al., 2003) to yield the highest point within an individual peak where red dots represent assumed individual trees. (c) Tree height data are extracted to yield heights of individual trees detected within each plot (red dots).

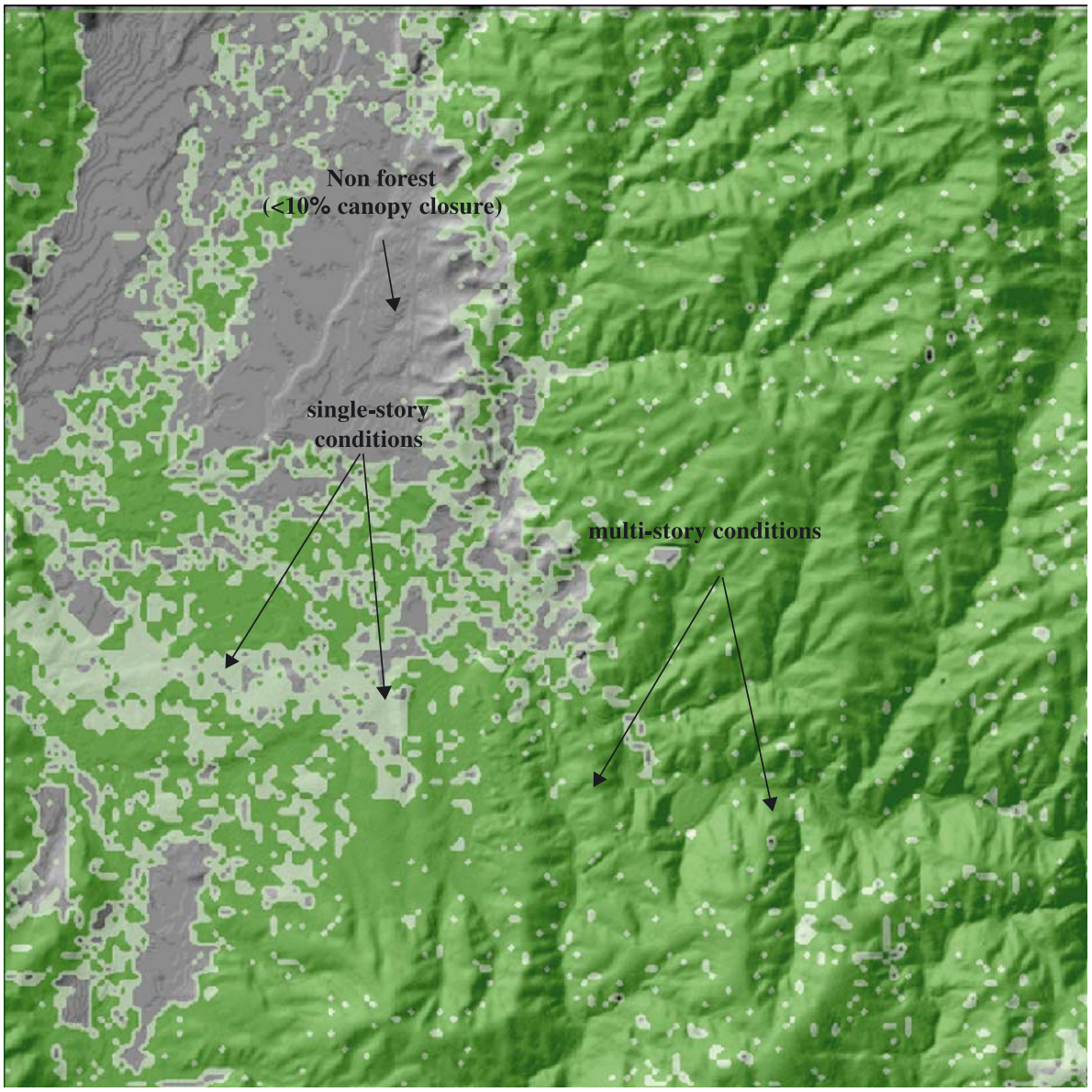

Fig. 3. Example of vertical structure classification (SW block) in study area near McCall, ID. Light green represents single-story class and dark green represents multistory class. 
height variances. This was done to verify that mapping forest vertical structures using LiDAR could be accomplished accurately. Levene's test was used because the total number of trees measured in the field vs. the total number of trees identified and measured in the LiDAR data on a perplot basis were different. Independent tests were run to compare single-story field and LiDAR plots and also multistory field against LiDAR plots.

\subsection{Classifying vertical forest structure}

Classifying the spatial distribution of vertical structure at the landscape scale through LiDAR analysis required the derivation of tree heights using the same methodology employed for the statistical analysis. A decrease in DEM resolution from 0.20 to $1.0 \mathrm{~m}$ was performed, and it was assumed that this would not affect the validity of the vertical structure mapping process. Cell size of the output tree height variance product $(30.0 \mathrm{~m})$ was based on the reduced number of tree heights detectable from 1.0-m resolution DEMs and an area large enough to encompass sufficient tree heights to calculate a variance. Furthermore, $30.0 \mathrm{~m}$ is a convenient resolution since it is the same resolution of many other data sets traditionally used in landscape-level analyses (e.g., U.S. Geological Survey $30.0 \mathrm{~m}$ DEM and Landsat ${ }^{\mathrm{TM}}$ data).

The two structure classes were based on the median value between the minimum tree height variance observed in the multistory plots $(2.75 \mathrm{~m})$ and the maximum tree height variance observed in the single-story $(1.21 \mathrm{~m})$ plots. Thus, each $30.0-\mathrm{m}$ cell in the tree height variance data set was classified as single-story $(<1.54 \mathrm{~m})$ or multistory (>1.54 m) (Fig. 3).

An accuracy assessment was produced for the classification using twenty-nine 0.10 -acre $(0.04$-ha) validation plots tallied for tree heights during the summer 2001 field season. Plot locations were chosen randomly within $100.0 \mathrm{~m}$ of roads only in the SW research block due to time constraints during that field season.

\section{Results}

Analysis of field tree heights demonstrated that tree height variance could be used as a measure to distinguish between two vertical structural classes within the different forest types (Fig. 4). The nonsignificant outcome of the

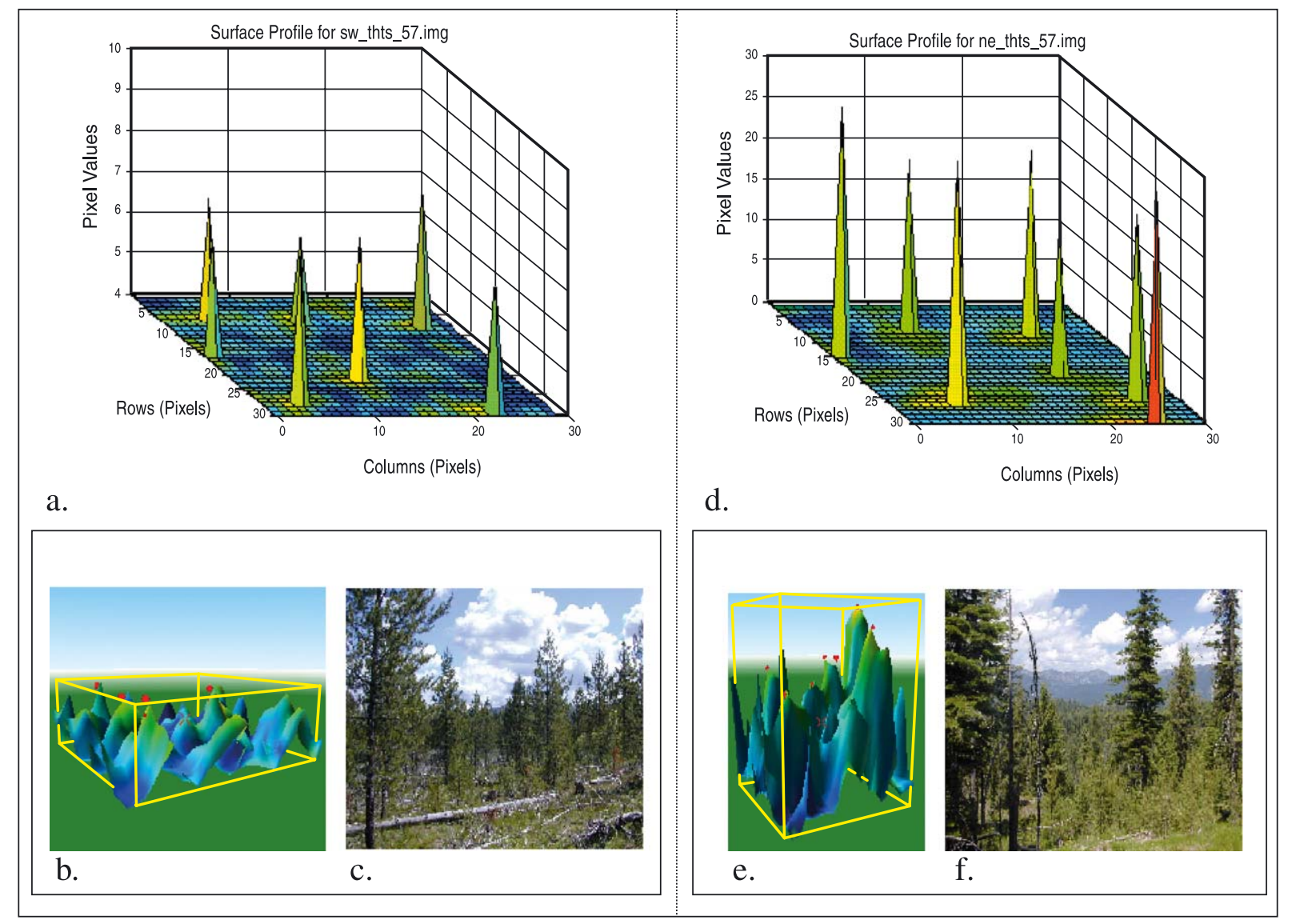

Fig. 4. Perspectives of single-story and multistory vertical structure classes from study area near McCall, ID. (a) Three-dimensional perspective of relative LiDAR-derived tree heights within a single-story plot. (b) Canopy surface from first return LiDAR data along with tree heights (red points) within a singlestory plot. (c) A typical single-story plot. (d) Three-dimensional perspective of relative LiDAR-derived tree heights within a multistory plot. (e) Canopy surface from first return LiDAR data along with tree heights (red points) within a multistory plot. (f) A typical multistory plot. 
ANOVA (Levene's test) indicated that single-story plots measured in the field were, in fact, single-story (i.e., plotlevel tree height variances were not significantly different from each other; $p>0.6102$ ). The GLM test confirmed that single-story and multistory plots measured in the field could be distinguished from each other based on their tree height variances $(p<0.0001)$.

Confirmation of differences between single-story and multistory classes in the field data bolsters the assertion that LiDAR-derived tree heights can be used to distinguish between vertical structural classes. Thus, the same series of tests were used to examine LiDAR-derived tree heights. For single-story LiDAR plots, however, the resulting ANOVA was significant (i.e., tree height variances between the plots were significantly different based on the test result; $p=0.0204$ ).

The statistical difference in the LiDAR single-story variances may have resulted from the limited post spacing $(\sim 2.0 \mathrm{~m})$ acquired for this study. Post spacing accounts for how much detail is detected in the LiDAR data. In the field, height measurements were always made to the peaks of live crowns. The distance covered between two consecutive LiDAR shots could have been large enough to result in missing the top of one tree while detecting the top of another. The sides of some trees may have been detected as lower peaks in the canopy surface while the other trees were accurately measured. These inconsistencies in the LiDAR surface likely resulted in an increase in height variance for a given single-story plot (Fig. 5a). Moreover, the post spacing limitation surely had some affect on detecting the correct number of trees within a plot. Trees often occurred as clumps, in which case some may have been missed altogether. Conversely, the tree-finding model may have identified two tree peaks in the canopy surface where there should only have been one (e.g., trees with forked or dead tops; Fig. 5b). It is also possible that peaks detected in the canopy surface may have been detected as tops of trees but may have actually been from LiDAR returns inside the crown due to gaps within an individual crown or a narrow terminal. These factors explain why single-story tree heights measured in the canopy surface were not representative of actual tree heights observed in the field and led to a statistical difference in the final analysis.

The ANOVA on the single-story LiDAR plots resulted in a contradictory response compared to the single-story field plots. The GLM analysis comparing the single-story to multistory LiDAR plots was in agreement with the same field plot comparison. A significant difference was found between the tree height variances of the single-story and multistory LiDAR plots $(p<0.0001)$.

This finding suggests that LiDAR data can be used to distinguish between single-story and multistory vertical structural classes within the study area. Although a significant difference was detected by the GLM within the LiDAR-derived tree heights, they may not have been truly representative of the actual tree height variances observed in the field due to height variance possibly attributed to low post spacing. While tree height variance inflation in the single-story LiDAR plots was explained, tree height variances within the multistory LiDAR plots may have been reduced. The vast differences in overall tree height variances between these two vertical structural classes, according to the field data, are such that even if single-story and multistory LiDAR tree height variances were less divergent, a significant difference was still expected (Table 1).

Unlike single-story plots, tree height variances in multistory LiDAR plots may be lower when post spacings are relatively large $(\geq 2.0 \mathrm{~m})$. Large trees in multistory stands have a greater chance of being detected by LiDAR. Although the relatively low canopy closure in these forests increases the probability of small trees being visible from the air, they are less likely to be identified in low-density

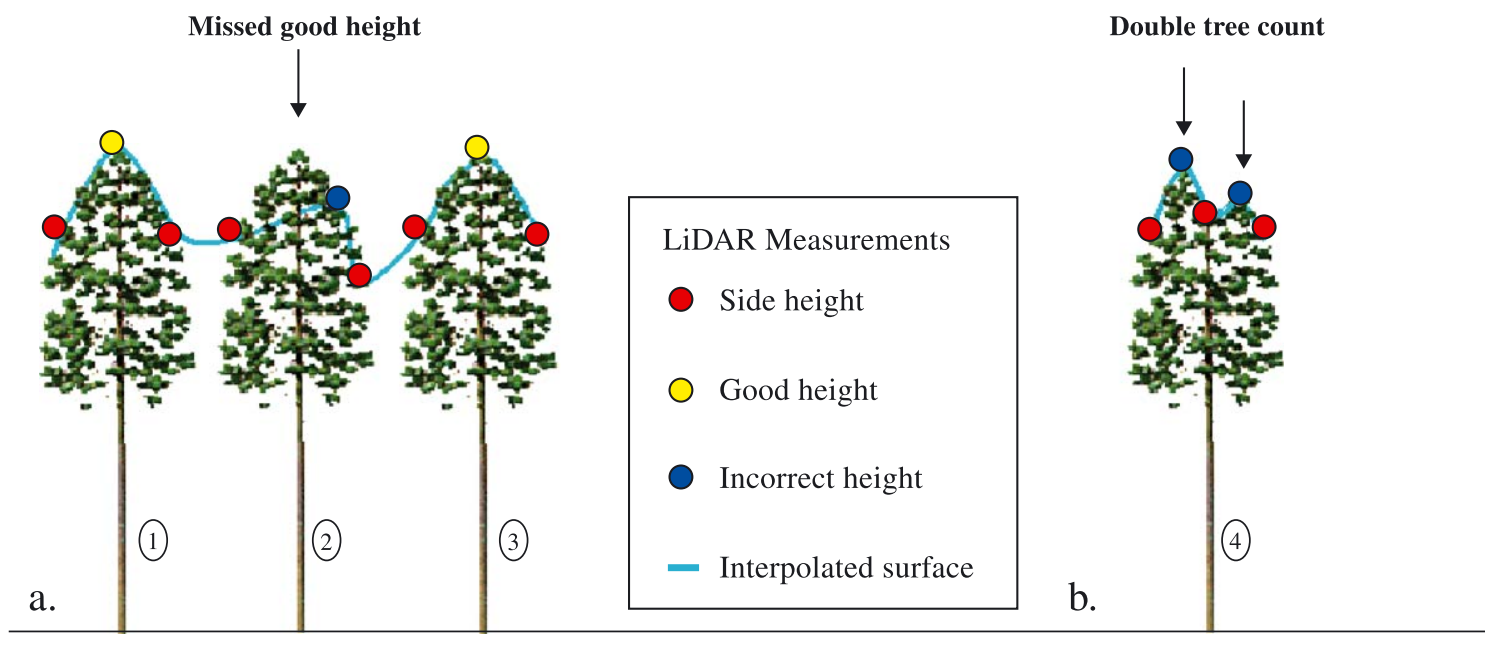

Fig. 5. Tree height variance can be inflated due to misperceived tree heights (from large post spacing) within the tree height-finding model. (a) Height of trees 1 and 3 is measured correctly because LiDAR returns intercept tree peaks (yellow). Height of tree 2 is incorrectly measured because the LiDAR return is from the side of the crown (blue). (b) Tree 4 is counted as two stems (and heights) due to a forked or irregular tree crown. 
Table 1

Summary of mean tree height, mean tree height variances, and standard deviation across both vertical structure classes for field and LiDAR plots near McCall, ID

\begin{tabular}{|c|c|c|c|c|}
\hline & $\begin{array}{l}\text { Single-story } \\
\text { field plots }\end{array}$ & $\begin{array}{l}\text { Multistory } \\
\text { field plots }\end{array}$ & $\begin{array}{l}\text { Single-story } \\
\text { LiDAR } \\
\text { plots }\end{array}$ & $\begin{array}{l}\text { Multistory } \\
\text { LiDAR } \\
\text { plots }\end{array}$ \\
\hline Mean tree height $[\mathrm{m}]$ & 8.50 & 18.36 & 6.60 & 17.52 \\
\hline $\begin{array}{l}\text { Mean tree height } \\
\text { variance }\left[\mathrm{m}^{2}\right] \\
(\mathrm{S} . \mathrm{D} ., \text { in } \mathrm{m})\end{array}$ & $\begin{array}{l}0.77 \\
(0.87)\end{array}$ & $\begin{array}{l}44.00 \\
(6.63)\end{array}$ & $\begin{array}{l}0.39 \\
(0.62)\end{array}$ & $\begin{array}{l}34.30 \\
(5.85)\end{array}$ \\
\hline
\end{tabular}

LiDAR data due to their small crown size with respect to coarse post spacing. This would contribute to lower variability in tree heights (Fig. 6). Ultimately, even though single-story and multistory tree height variances were not proportionally representative of observed field tree height variances, a significant difference between the two LiDAR vertical structure classes was still found. This further confirms the robustness of the LiDAR technique of vertical structure classification.

Concluding the series of statistical tests, a comparison between field and LiDAR tree height variances was performed. It was hypothesized that there would be no significant differences between field- and LiDAR-derived tree height variances for each structure class. This was based on the assumption that the reported underestimation of tree heights by LiDAR was consistent (Eggleston, 2001) and did not affect the actual dispersion of tree heights. However, the outcome of the ANOVA used to compare tree height variances resulted in a significant difference suggesting that
Table 2

Levene's test for homogeneity of tree height variance (single-story field vs. LiDAR and multistory field vs. LiDAR) ANOVA of squared deviations from group means* for tree data taken on plots near McCall, ID

\begin{tabular}{clrrll}
\hline & $\begin{array}{l}\text { Source of } \\
\text { variation }\end{array}$ & $d f$ & $\begin{array}{l}\text { Mean } \\
\text { square }\end{array}$ & $F$ value & $\begin{array}{l}\text { Pr>F } \\
\text { value }\end{array}$ \\
\hline Single-story field & Plot & 1 & 30.6 & $20.88^{* * *}$ & $<0.0001$ \\
vs. LiDAR & Error & 287 & 1.4 & & \\
Multistory field & Plot & 1 & 2065.6 & $0.58(\mathrm{NS})$ & 0.4471 \\
vs. LiDAR & Error & 1389 & 3572.6 & & \\
\hline
\end{tabular}

* Level of significance: $\mathrm{NS}=$ significant $(\alpha=0.05)$.

$* * *=$ significant $(\alpha=0.001)$.

the single-story field and LiDAR tree height variances were not the same. While this was in contradiction to what was expected, the explanation of how large LiDAR post spacings can yield inflated tree height variances probably accounts for the result. For this study, tree height measurement in LiDAR data, and therefore variance estimation, was a function of tree identification in canopy surfaces. Low posting densities resulted in incorrect heights of identified trees and missed heights due to trees not identified in the canopy surface (Fig. 6). Tree height was consistently measured to the top of live crowns; therefore it, was possible to demonstrate that single-story field plots were one vertical structure class. For the reasons given above, this was not the case with the LiDAR measurements.

Inconsistencies between single-story field and LiDAR tree height variances would lead one to expect significant differences between the two classes $(p<0.0001$; Table 2). The ANOVA comparison between multistory field and

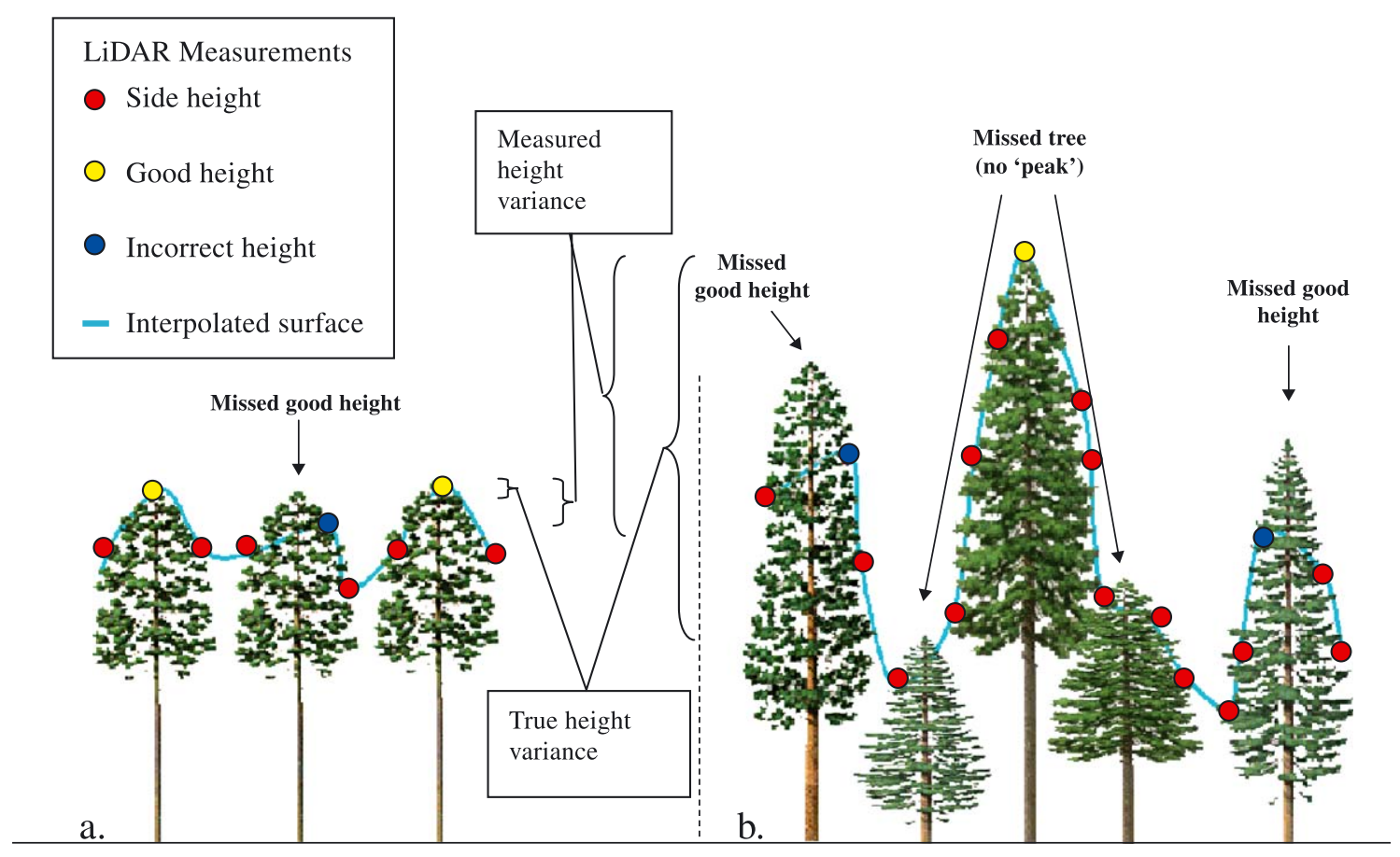

Fig. 6. Large post spacings can influence tree height variances due to incorrect tree heights within the tree height-finding model. This can still result in significant differences between single-story and multistory LiDAR plots. (a) Inflated single-story tree height variance due to incorrect tree height measurements (blue dot). (b) Reduced multistory tree height variance due to incorrect tree height measurements. 
Table 3

Accuracy assessment of vertical structure classes in study area near McCall, ID

\begin{tabular}{lcccc}
\hline $\begin{array}{l}\text { Vertical } \\
\text { structure } \\
\text { class }\end{array}$ & $\begin{array}{l}\text { Reference } \\
\text { totals }\end{array}$ & $\begin{array}{l}\text { Classified } \\
\text { totals }\end{array}$ & $\begin{array}{l}\text { Producer's } \\
\text { accuracy [\%] }\end{array}$ & $\begin{array}{l}\text { User's } \\
\text { accuracy [\%] }\end{array}$ \\
\hline $\begin{array}{l}\text { Single-story } \\
\text { Multistory }\end{array}$ & 5 & 6 & 100 & 83 \\
\hline
\end{tabular}

LiDAR tree height variances, although potentially plagued by the same variance influences that affected single-story plots, did not result in a significant difference $(p=0.4471$; Table 2). While there was inconsistency of overall tree height dispersion between multistory plots, the magnitude of the variances in both the field and LiDAR measurements contributed to a failure to detect differences.

The accuracy assessment of the landscape-level classification depicted in Fig. 3 revealed a significant agreement between reference and classified plots of single-story and multistory conditions. Producer's accuracy (a measure of how consistent reference plots compare to classification plots; Congalton \& Green, 1998) was very high for both single-story and multistory classes as was user's accuracy (a measure of how likely a pixel was correctly classified with regard to the same class type on the ground) (Table 3 ). The overall classification accuracy was $97 \%$ and the overall $\kappa$ statistic was 0.89 . Although it was not possible to complete a thorough accuracy assessment with a large number of validation plots, the results suggested that LiDAR data could be used to map vertical structure accurately at landscape scales.

\section{Discussion and conclusions}

This study demonstrated that field-derived tree height variances could be used to distinguish between single-story and multistory classes of vertical structure within forests of the study area and, presumably, other parts of the Intermountain West. Results also suggested strongly that LiDARderived tree height variances could be used to differentiate these two structure classes presumably at the landscape scale. While this study's methods showed that distinguishing between single-story and multistory classes using LiDAR is possible, they do not necessarily represent the underlying continuous nature of vertical structure. For practical purposes, the multistory class was referred to as a single class, although, realistically, it represents a range of conditions that occur in forested areas. The thematic classification of vertical structure into single-story and multistory classes may be sufficient in some applications, but a more realistic approach for representing vertical structure would be to characterize its spatial distribution continuously.

One method of characterizing vertical forest structure as a continuous surface is to employ the coefficient of variation (CV) of LiDAR-derived tree heights. Lantham, Zuuring, \&

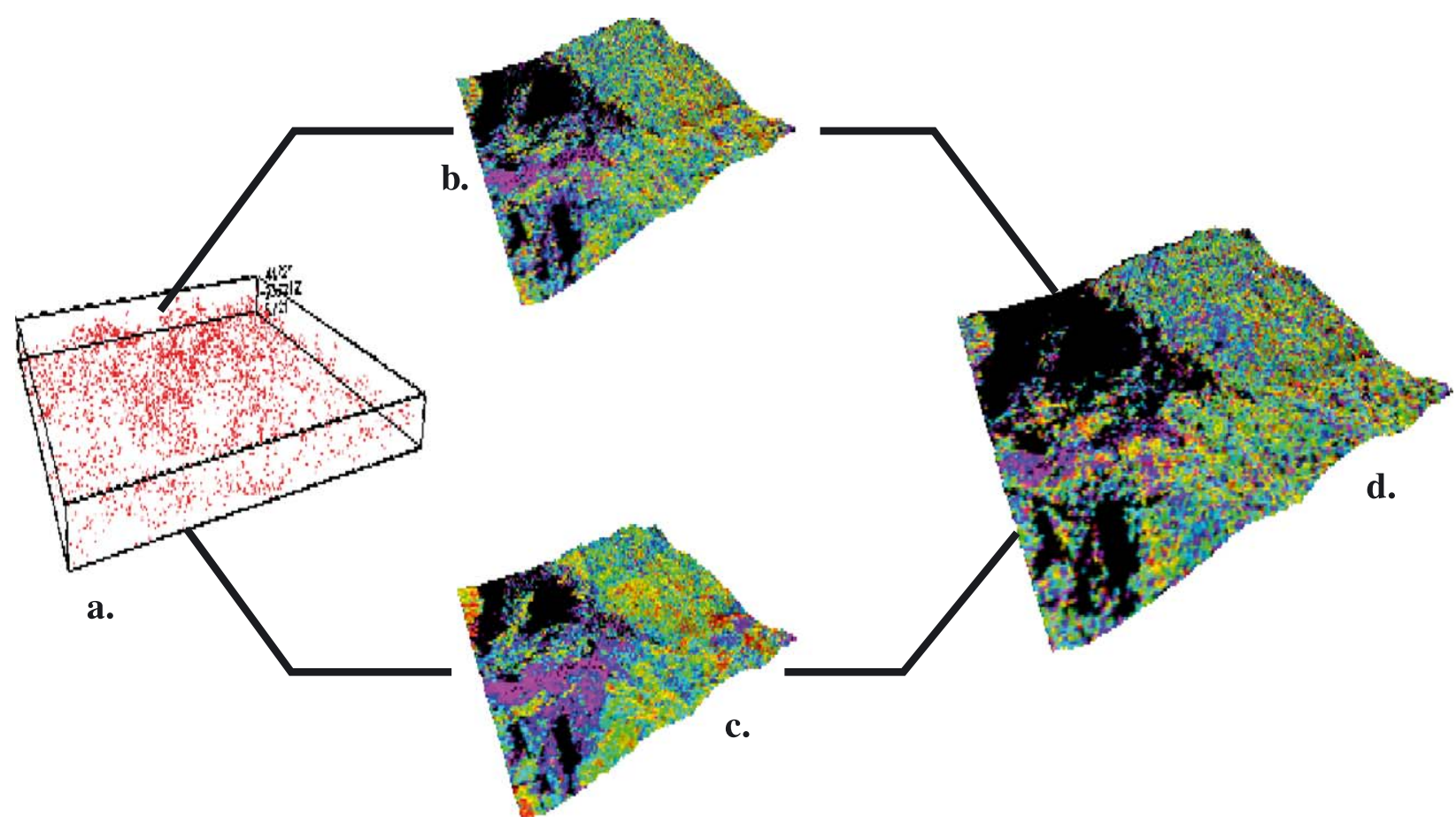

Fig. 7. Methods used to characterize vertical forest structure as a continuous surface. (a) Raw tree heights were derived using the tree height-finding model. Tree heights were used to create a tree height standard deviation data set (b) and a mean tree height data set (c). Dividing the tree height standard deviation data set by the mean tree height data set and multiplying by 100 produced the CV data set (d). 
Coble (1998) chose CV based on its use in quantifying vertical structure with standard inventory data. This unitless ratio between the standard deviation and mean of tree heights is a measure of dispersion that is independent of sample size and can be used to compare samples of unequal sizes.

To examine the potential utility of the $\mathrm{CV}$, it was developed in a fashion similar to the derivation of the tree height variance data set. The CV data set was produced in ARC/INFO GRID by dividing the standard deviation tree height data set by the mean tree height data set and multiplying by 100 (Fig. 7). Cell size was chosen to be 30 $\mathrm{m}$ based on the same minimum data requirements as the tree height variance data set.

Although it was demonstrated that coarse LiDAR data ( $\geq 2 \mathrm{~m}$ spacing) inflate or depress measured tree height dispersion within a forest stand, they nonetheless were useful in determining height detail differences at the landscape scale (Fig. 8). It was evident that LiDAR data can be used to detect a variety of vertical structure configurations from relatively low $\mathrm{CV}$ within thinned, single-story areas (dark blue to light green) to relatively high CVs within diverse multistory areas (orange to red). It was observed in the field that a majority of the areas coded as red (or high CVs) follow drainages/depressions that contain more "cool-moist" conditions and a greater degree of multicohort forest types observed as having a greater diversity of tree heights.

The benefit of a continuous description of vertical structure within spatially based DSS, such as EDM, includes the ability to accurately relay the realistic nature of vertical structure across the forested landscape. Accurate characterization of vertical structure conditions that exist within a given planning landscape, such as the ISBL, can provide valuable information to decision makers so they can achieve a variety of goals in a sustainable manner. For example, while primary goals may be aimed at commodity extraction, the necessity to achieve this goal in a sustainable way requires that certain ecological processes remain reasonably undisturbed. In regards to vertical structure, this may require a proportional representation of various vertical structural configurations at all times within the planning landscape to maintain desirable elements of biodiversity, which foster selfsustaining ecosystem processes essential for the continuous productivity of forest commodities and other outputs.

Although there are limitations in using LiDAR data with large post spacings $(\geq 2.0 \mathrm{~m})$ in detecting various levels of vertical structure, it was possible to distinguish between the

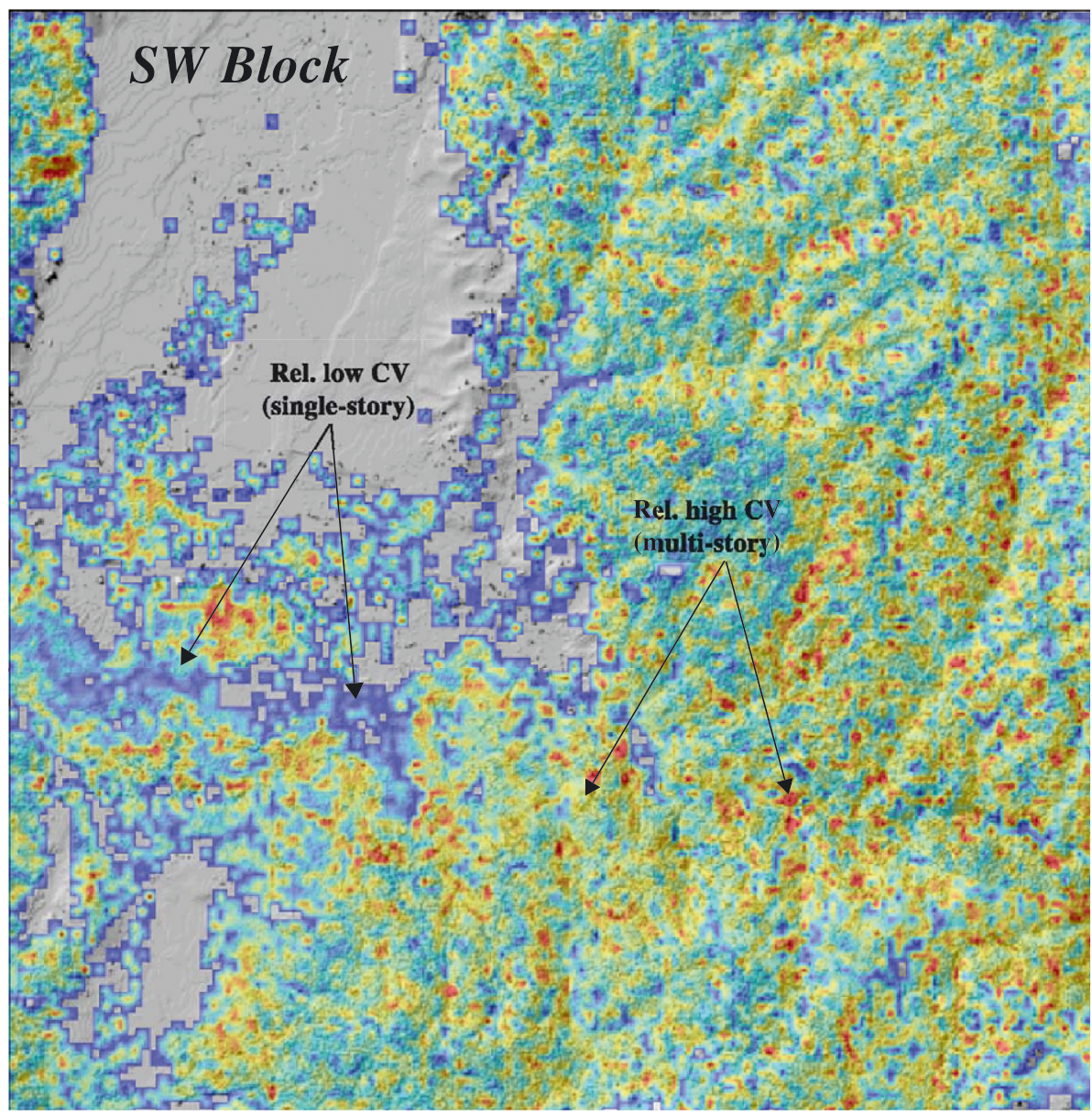

Fig. 8. Example of the continuous distribution of forest complexity derived from LiDAR data (SW block) of study area near McCall, ID. The chromatic gradient represents low (blue) to high CV (red). 
two structure classes examined in this study. With this type of information and at the level of detail LiDAR data can provide, it was possible to map vertical structure at landscape scales with enough detail to be useful in a variety of applications. However, one must recognize that post spacings smaller than those used in this study are deemed preferable. In Intermountain West forests, high-density LiDAR data could be used to detect far more detail than was apparent with data used in this study (Fig. 9). However, the derivation of tree height variances from LiDAR data with relatively large post spacings does demonstrate its usefulness in producing accurate data sets that capture the thematic/continuous spatial distribution of vertical structure.

LiDAR data sets have application in the evaluation of different resource management prescriptions at landscape levels. The DSS discussed earlier requires specific information on multiple landscape parameters. This study demonstrated that LiDAR data can provide one parameter, vertical forest structure, for determining vegetative growth stages (VGS) in Boise Cascade's EDM. Another application of LiDAR is in assessing habitat suitability for selected wildlife species. These could include: (1) rare and endangered species, (2) threatened species, (3) species of high public visibility or demand, or (4) indicator species of selected ecological conditions. By modeling habitat suitability for selected species, the spatial distribution of critical life requisites (i.e., nesting, breeding, and foraging habitat) could be evaluated under various land management prescriptions and scenarios. In this way, landscapes may be managed at the ecosystem level, working toward identifying the appropriate mix of ecological, economic, and social objectives within the landscape.

LiDAR data can be used to generate a suite of habitat variables or attributes for input into spatial models of habitat suitability. Stand-level attributes such as tree height, vertical structure, canopy closure, and density can be generated from LiDAR data. Work is progressing on fusing LiDAR data sets with high-resolution multispectral imagery to generate other habitat variables such as species composition and diversity, and snag and coarse woody debris identification and quantification.

Continuation of the work initiated by this study involves the development of species habitat models driven by remotely sensed data sets, LiDAR, and high-resolution multispectral imagery. The goal of these efforts is the development of an application concept in the form of a DSS that can be applied at the landscape level to assess habitat suitability. It is recommended that research continue to investigate how LiDAR data with higher posting densities can be used to derive this type of information more accurately. It is also recommended that research explore the development of horizontal forest structure (e.g., stem density and canopy closure) variables using LiDAR systems.

The study results indicated that continuing research in these areas leveraging the capability of LiDAR systems for detecting and measuring the organization of objects in three dimensions (in this instance forests) should lead to a variety of improvements in forestry and wildlife management

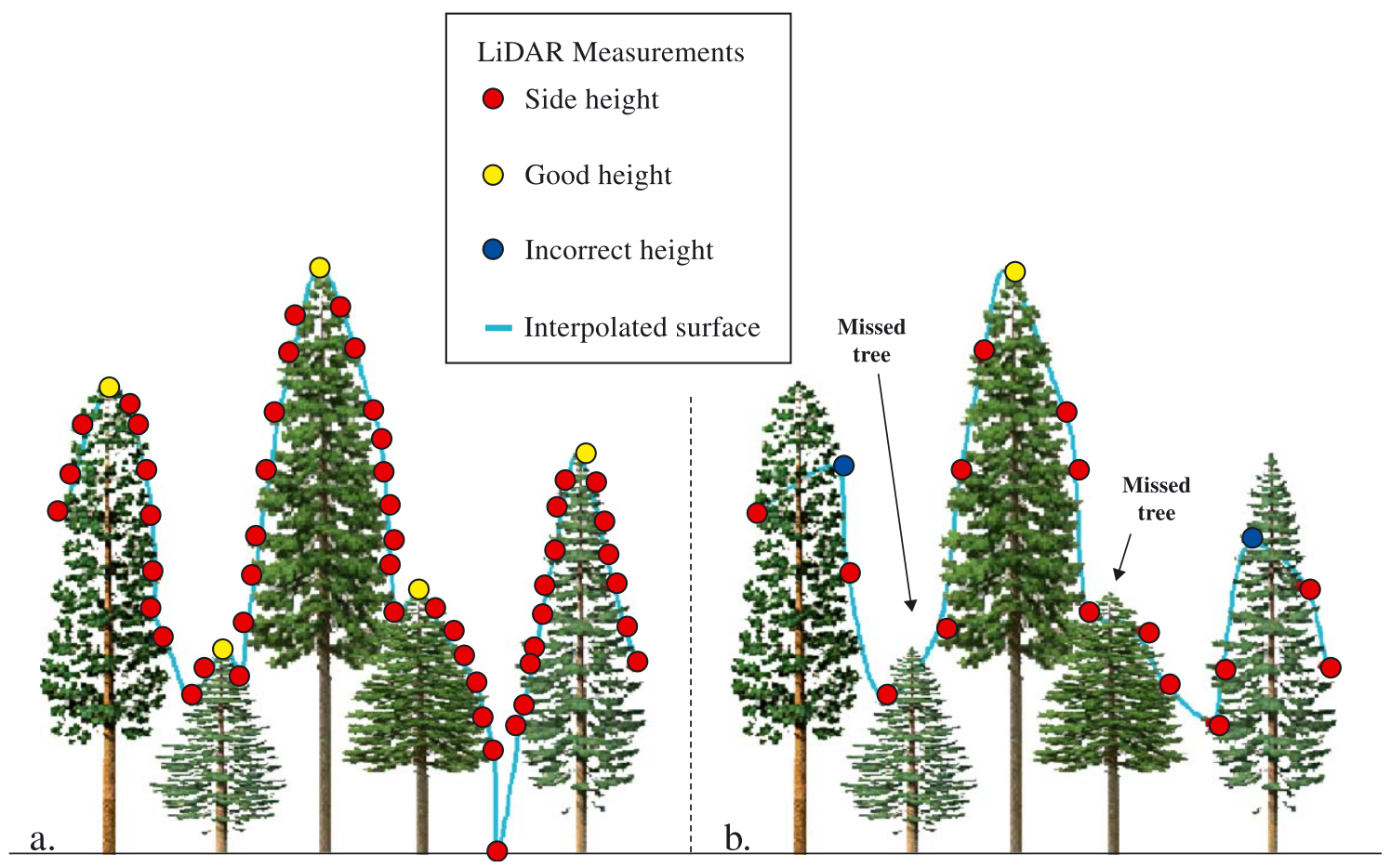

Fig. 9. LiDAR with smaller post spacings would yield better results with regard to detecting the dispersion of tree heights. (a) Accurate estimate of tree height dispersion due to a small post spacing $(<2.0 \mathrm{~m})$. (b) Less accurate estimate of tree height dispersion due to large post spacing $(\geq 2.0 \mathrm{~m})$. 
including more accurate habitat models, increases in classification accuracies of spectral data, and enhanced decisionsupport systems.

\section{Acknowledgements}

This research was supported by the U.S. Forest Service, Southern Research Station, under cooperative research agreements SRS 33-CA-99-589, 00-CA-11330145-230, and 01-CA-11330145-377. Special thanks are extended to Dr. Bill Cooke of the Southern Research Station for support of these efforts.

This paper has been approved for publication as journal article FO220 of the Forest and Wildlife Research Center, Mississippi State University.

\section{References}

Brandtberg, T., Warner, T. A., Landenberger, R. E., \& McGraw, J. B. (2002). Detection and analysis of individual leaf-off crowns in small footprint, high sampling density LiDAR data from eastern deciduous forest in North America. Remote Sensing of Environment, 85, 290-303.

Brokaw, N. V. L., \& Lent, R. A. (1999). Vertical structure. In M. L. Hunter (Ed.), Maintaining biodiversity in forest ecosystems (pp. 373-399). Cambridge, UK: Cambridge University Press.

Congalton, R. G., \& Green, K. (1998). Assessing the accuracy of remotely sensed data: Principles and practices. New York: Lewis Publishers, $137 \mathrm{pp}$.

Eggleston, N. (2001). Tree and terrain measurements using small-footprint multiple-return airborne LiDAR data from mixed Douglas-fir forest in the Pacific Northwest. Master's Thesis. Mississippi State, MS: Mississippi State University, $135 \mathrm{pp}$.

Haufler, J. B., Mehl, C. A., \& Roloff, G. J. (1999). Conserving biological diversity using a coarse-filter approach with a species assessment. In R. K. Baydack, H. Campa III, J. B. Haufler (Eds.), Practical approaches to the conservation of biological diversity (pp. 107-125). Washington, DC: Island Press.

Hudak, A. T., Lefsky, M. A., Cohen, W. B., \& Berterretche, M. (2002). Integration of LiDAR and Landsat ETM + data for estimating and mapping forest canopy height. Remote Sensing of Environment, 82, 397-416.

Hyyppä, J., Kelle, O., Lehikoinen, M., \& Inkinen, M. (2001). A segmentation-based method to retrieve stem volume estimates from 3-D tree height models produced by laser scanners. IEEE Transactions on Geoscience and Remote Sensing, 39(5), 969-975.

Kraus, K., \& Pfeifer, N. (1998). Determination of terrain models in wooded areas with airborne laser scanner data. Journal of Photogrammetry and Remote Sensing, 53, 193-203.

Lantham, P. A., Zuuring, H. R., \& Coble, D. W. (1998). A method for quantifying vertical forest structure. Forest Ecology and Management, 104, 157- 170 .

Lefsky, M. A., Cohen, W. B., Acker, S. A., Parker, C. G., Spies, T. A., \&
Harding, D. (1999). LiDAR remote sensing of the canopy structure and biophysical properties of Douglas-fir western hemlock forests. Remote Sensing of Environment, 70, 339-361.

Levene, H. (1960). Robust test for equality of variances. In I. Olkin, S. G. Ghurye, W. Hoeffding, W. G. Madow, \& H. B. Mann (Eds.), Contributions to probability and statistics: Essays in honor of Harold Hotelling (pp. 278-292). Stanford, CA: Stanford University Press.

Martin, T. E. (1988). Habitat and area effects on forest bird assemblages: Is nest predation an influence? Ecology, 69(1), 74-84.

Maurer, B. A., \& Whitmore, R. C. (1981). Foraging of five bird species in two forests with different vegetation structure. Wilson Bulletin, 93(4), $478-490$.

McCombs, J., Roberts, S., \& Evans, D. (2003). Influence of fusing LiDAR and multispectral imagery on remotely sensed estimates of stand density and mean tree height in a managed lobiolly pine plantation. Forest Science, 49(3), 457-466.

McCoy, E. D., \& Bell, S. (1991). Habitat structure: The evolution and diversification of a complex topic. In S. Bell, E. D. McCoy, \& H. R. Mushinsky (Eds.), Habitat structure: The physical arrangement of objects in space (pp. 3-27). London, UK: Chapman and Hall.

Means, J. E., Acker, S. A., Harding, D. J., Blair, J. B., Lefsky, M. A., Cohen, W. B., Harmon, M. E., \& McKee, W. A. (1999). Use of largefootprint scanning airborne LiDAR to estimate forest stand characteristics in the Western Cascades of Oregon. Remote Sensing of Environment, 67, 298-308.

Mehl, C. A., Steele, R., Warren, S., Holt, B., Haufler, J. B., \& Roloff, G. J. (1998). The ecosystem diversity matrix for the Idaho Southern Batholith Landscape: A user's manual. Boise, ID: Boise Cascade.

Næsset, E. (2002). Predicting forest stand characteristics with airborne scanning laser using a practical two-stage procedure and field data. Remote Sensing of Environment, 80, 88-99.

Næsset, E., \& Økland, T. (2002). Estimating tree height and tree crown properties using airborne scanning laser in a boreal nature reserve. Remote Sensing of Environment, 79, 105-115.

Nelson, R., Krabill, W., \& Tonelli, J. (1988). Estimating forest biomass and volume using airborne laser data. Remote Sensing of Environment, 24, $247-267$.

Nilsson, M. (1996). Estimation of tree heights and stand volume using an airborne LiDAR system. Remote Sensing of Environment, 56, 1-7.

Parker, R. C., \& Evans, D. L. (in press). An application of LiDAR in a double-sample forest inventory. Western Journal of Applied Forestry.

Persson, Å., Holmgren, J., \& Söderman, U. (2002). Detecting and measuring individual trees using an airborne laser scanner. Photogrammetric Engineering and Remote Sensing, 68(9), 925-932.

Petzold, B., Reiss, P., \& Stossel, W. (1999). Laser scanning-surveying and mapping agencies are using a new technique for the derivation of digital terrain models. International Society of Photogrammetry and Remote Sensing Journal of Photogrammetry and Remote Sensing, 54, 95-104.

Popescu, S. C., Wynne, R. H., \& Nelson, R. F. (2002). Estimating plotlevel tree heights with LiDAR: Local filtering with a canopy-height based variable window. Computers and Electronics in Agriculture, $37(1-3), 71-95$.

Robinson, S. K., \& Holmes, R. T. (1982). Foraging behavior of forest birds: The relationships among search tactics, diet and habitat structure. Ecology, 63(6), 1918-1931. 